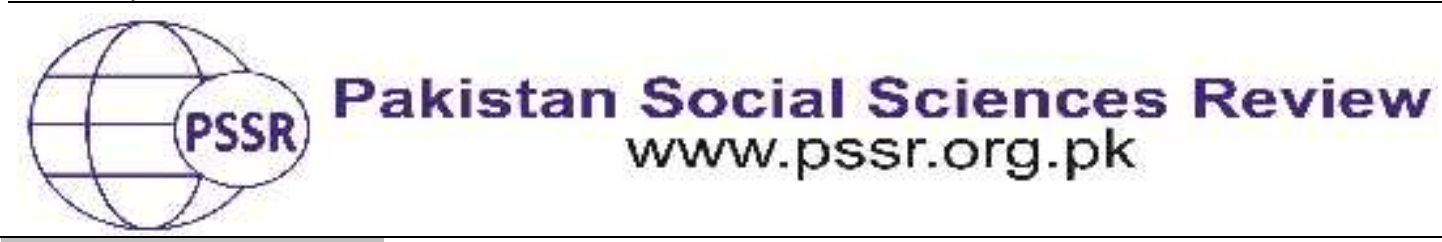

RESEARCH PAPER

\title{
Psychodynamic Analysis of Early Childhood Teachers and their Professional Development: Evidence from Pakistan
}

\author{
Nuzhat Naz ${ }^{1}$ Prof. Dr. Muhammad Yousuf Sharjeel ${ }^{2}$
}

1. PhD Scholar, Department of Education, Hamdard University, Karachi, Sindh, Pakistan

2. Professor, Faculty of Social Sciences and Education, Department of EducationSZABIST-Karachi, Sindh, Pakistan

\begin{tabular}{|c|c|}
\hline & \\
\hline & \multirow{15}{*}{$\begin{array}{l}\text { he objective of current research is to examine the relationship } \\
\text { etween the ECE teacher's competency and their professional } \\
\text { levelopment. A mixed method approach was adopted to } \\
\text { dminister various strategies in the study. Research protocols } \\
\text { vere adopted. Consent letters were sent to the respondents. A } \\
\text { ample of randomly selected } n=160 \text { early childhood education } \\
\text { eachers from all the provinces of Pakistan were asked to } \\
\text { omplete the questionnaire. For collecting data, quantitative } \\
\text { nalytical techniques were used. Data was collected through } \\
\text { eview of the related literature, discussion and consultation with } \\
\text { takeholders administering questionnaire to early childhood } \\
\text { ducation teachers. The numerical data were analyzed through } \\
\text { PSS. Results revealed a pattern of significant relationships } \\
\text { etween the psychodynamic characteristics and professional } \\
\text { levelopment of the early childhood education teachers. The } \\
\text { tudy concludes that more efforts are require towards the } \\
\text { rofessional development of early childhood education teachers } \\
\text { or better learning of young children because these years (2-5 } \\
\text { ears) are the milestone of any human life }\end{array}$} \\
\hline & \\
\hline & \\
\hline & \\
\hline & \\
\hline & \\
\hline & \\
\hline & \\
\hline & \\
\hline & \\
\hline & \\
\hline & \\
\hline & \\
\hline & \\
\hline & \\
\hline
\end{tabular}

\section{Introduction}

The ECD training is a recent and positive step by the Government of Pakistan. The former Katchi classes for the primary kids have now been converted to the terms known as ECE and ECD classes. The training of the teachers is done for two years which is not sufficient to adequately justify for the forming and dealing of the impressionable young minds as it takes not only teaching them through educational objects, but also teaching the kids of pre-primary with motherly feelings, wisdom and patience. Continuous professional development of the teachers of ECE and ECD teachers should be carried on regularly so as the teachers can be in touch with, and be the deliverers of the latest knowledge and skills to the young 
generations entering the ECE and ECD systems. The overcrowded classes of the young learners with different personalities and reactions are a test of impregnable patience for the teacher trained for the preprimary. The teacher might have received specialized training of two years, but the unexpected outcome of dealing with such a large audience beyond her expectations becomes something which is just too much for the teacher to chew on.

Early childhood education is a new phenomenon in Pakistan, but it is historically significant. Since the time that its autonomy from the subcontinent in August 1945, the administration of Pakistan is variably as well as reliably focusing on its resolve to accomplish cent percent enlistment of school age kids at the Primary and Secondary school levels. According to Pakistan Education Statistics 2014-15, there are total 8.635 million children at pre-primary stage in Pakistan, out of which 4.6 million are enrolled in public sector schools while over four million children in private. The latest economic survey estimates pre-primary enrolment in Pakistan to 9.61 million during 2016.

It is known that if the early childhood education practitioner is professionally developed; gathering student observation data in shape of studies provides teachers with opportunities to reflect on the classroom environment, curriculum, and teaching strategies. The aim of this study is to find out the impact of psychodynamic characteristics of early childhood education Teachers on their own professional development(Ritz, et, al., 2014). The researcher aims to observe the teacher's psychodynamic characteristics in early childhood education setting for the holistic development of their students. The data for research was extracted from extensive documentation available and by conducting a survey developing a questionnaire among early childhood education teacher in Pakistan.

Many of us are able to remember our earliest childhood and our favourite early childhood teacher: the one who made us welcome, who dried our tears, comforted us when we had bruised and taught us our first understanding of right and wrong. Moreover, we could clearly recall that we had a strong emotional bond with that significant other or in what way that exact person influenced us. Similarly, every early childhood Education teacher has her own professional motivation and kind of psychodynamic that enable them to pursue the primary goal of satisfying children's' needs.

The experiences of EC practitioner and children makes us wonder what kind of psychodynamic does EC teacher need to have to make such positive influence on the child? Even more, if we want to describe typical early childhood education teacher's psychodynamics within the modern psychodynamic theories, what that description would be? What kind of psychodynamic traits would have a typical early childhood education teacher, or the most liking one? Generally, psychodynamics could be defined as a cluster of traits that determine individualspecific responses to the environment and make human behaviour and experiencing 
more consistent. Psychodynamics has been conceptualized from a variety of theoretical perspectives. Each of these psychodynamic models has made unique contributions to our understanding of individual differences in behaviour and experience and tried to embrace as wide a range of human behavioural patterns as possible by its limited system of assumptions or constructs. Two psychodynamic models are dominant and concurrent paradigms in psychodynamic research (Goldberg, 2007).

\section{Background of the Study}

The beginning of early childhood development is historically significant. Normal child consideration is found to have the little introductory consequences for kids' learning and improvement. Ordinarily, family day consideration homes demonstrate no impact on psychological advancement, while youngster consideration focuses create little transient impacts on subjective and dialect improvement. A few non-test studies in the global communities have discovered focus based child consideration to create little negative preschool training and its enduring impacts 6 of 35 consequences for social-enthusiastic advancement and conduct-specifically, expanded hostility. Some confirmation are negative impacts increment with number of years in consideration, however reduce when kids go to higher quality projects.

What's more, a few concentrates, however not all, discover bigger advantages for kids from financially impeded families. These discoveries are from non-test concentrates, on the other hand; impacts may be affected by in secret contrasts in the middle of youngsters and families who do and do not utilize kid care.The methodologically most grounded long haul investigation of youngster care's belongings in the United States finds that both positive and negative impacts tend to decay after some time. The weaker Early Childhood Longitudinal Study Kindergarten Cohort of 1998 (ECLSK) studies observe that inside based projects have little remaining impacts on perusing and math test scores until the end of third grade (Sylva et al, 2010).

It is by and large perceived that the effects of what happens in the midst of the pre-natEarly Childhood Education (ECE)Emotional information is in the blink of an eye saw as crucial for enlightening accomplishment. Understudies who have bigger measure of eager learning will likely remain and continue with guideline. It is truly a period for maintaining and enabling the child's spirit.

\section{Review of Literature}

\section{The Basic Debate of ECE}

There is limited research about what makes a good Early Childhood Education teacher especially in terms of the professional development of EC practitioners due to psychodynamic traits. Since the process of early learning and 
teaching is far more complex, it is crucial to analyze ECD teacher's psychodynamic traits.Ackerman\& Maslin-Ostrowski (2002)and Ackerman(2019) say that he early childhood education teacher-child interaction and whole climate of kindergarten group directly depend upon Early Childhood Education teachers' psychodynamic traits. Her psychodynamic influences on her sensitivity to the Early Childhood practitioner's psychodynamic are in its formative stages. This is very important because pre-schoolers will only learn when they are in a trusting environment.

\section{Eysenck's Psychodynamic Theory}

Even though Eysenck's psychodynamic theory had its peak dominance in seventies and eighties in previous century, it still has been intriguing in the field of psychodynamic psychology. It has its roots in rigorous empirical results from factor analyses of various psychodynamic traits' indicators and measure instruments. Eysenck's theory is based on the physiological findings from Pavlov's research of classical conditioning, and on the concepts of excitation-inhibition and arousal hypotheses. According to that, he claimed that psychodynamic traits actually reflect individual differences in the ways that peoples' nervous systems operate.

The greatest contribution of Eysenck's theory is in the possibility of detecting genetic factors and of determining the universality and stability of psychodynamic dimensions. An introverted psychodynamic is quiet, unsociable, passive and careful; an extroverted psychodynamic is talkative, lively, active, optimistic, sociable and outgoing. Psychoticism is described by characteristics such as aggressive, more ruthless, egocentric, insensitive, antisocial, impulsive and tough-minded.

\section{Five-Factor Model of Psychodynamics}

It seems that researchers, who tried to solve the problem of lack of paradigm in psychodynamic psychology, which consequently resulted with too many psychodynamic theories, have succeeded. Therefore, the discovery of five basic dimensions of psychodynamic called Big Five (Goldberg, 2007) is considered as the one of the most important events in $20^{\text {th }}$ century in psychodynamic psychology. The Big Five model is substantially descriptive, with the emphasis on the taxonomic aspect. It is based on Galton's lexical hypothesis which presumed that the most important individual differences in human transactions would be noted as separate words in some or all world languages (Goldberg, 2007). In other words, it was supposed that psychological and social realities were adequately reflected through the language,

\section{ECE and Big Five Dimensions of Psychodynamics}

A certain number of studies demonstrated that extraversion and emotional stability from Big Five model are congruent to extraversion and neuroticism from the Eysenck's model. Armstrong (2007) is followed in concepts about ECE education by Ashraf (2013) and Aubrey (1998) with regards to training of ECE and ECD teachers. 
As it was mentioned earlier, there is a big lack of systematic and scientific exploration of Early Childhood Education teacher's psychodynamic.

\section{Professional Practices and ECD}

According to Pianta (2012), there are different versions of thoughts towards early childhood education and they provide the importance of needs as well as the interests of students to learn their skills for the support of educational requirement based on theories and practices. Farooq (2017) kept up that early youth training is likewise rehearse, it is a shape the idea of ahead of schedule youth training is best of all known. Despite duties and advancement in enhancing access to training at the worldwide level, who have put in no less than four years in school. Current and future worldwide improvement objectives, including instruction objectives, might be met with regard for the general advancement of youthful kids.

\section{Stages of Children's Development}

Piaget's described four stage of development. The sensory motor stage happens in the middle of conception and two years old. Newborn children utilize all their faculties to investigate and learn. Along these lines, tangible encounters and motor development advance cognitive development. Babies' physical activities, for example, sucking, getting a handle on, and hitting, help them look into their surroundings. Developments are irregular from the beginning. Bit by bit, they get to be deliberate as practices are rehashed. Youngsters start to discover that questions still exist actually when they are far away. This is known as article changelessness. Through investigation and introduction to new encounter, new ideas are educated.

Bertsch, Houlihan, Lenz, \& Patte (2017) agree that the preoperational stage happens between ages two and seven. Children during this stage are exceptionally egocentric. Newcomb \& Ritter (2011) also raised issue of child development through formal training. Both Jean Piaget and Lev Vygotsky acknowledged that adolescents fabricate learning through experience. Piaget acknowledged this happened through examination with dynamic activities. Vygotsky, on the other hand, acknowledged that kids learn through social and social encounters. Association with companions and adults helps youths in this technique. While interfacing with others, youngsters take in the conventions, qualities, feelings, and tongue of their general public. Subsequently, families and teachers should give a considerable measure of social joint effort to pre-adult youngsters.

\section{Types of Development in Children}

Gross-engine improvement incorporates change of aptitudes using the gigantic muscles as a piece of legs and arms. Such developments as running, skipping, and bike riding fall into this class. Fine-engine improvement incorporates the little muscles of the hands and fingers. Understanding, holding, cutting, and drawing are a couple of activities that manufacture fine-engine advancement. The 
researchers believe that learning in an ECE context is possible when the contents address the emotional well-being of children to express their emotions and feelings in a learning situations. In order for children to get the essential ability that they need such as collaboration, following directions, representative self-discipline and paying and concentration they must have social-emotional skills. Feelings of trust, self-assurance, satisfaction, companionship, warmth are parts of this phase of life.

Bereiter \& Engelmann (1998) say that emotional security is a key factor for the learner in early school settings. Acceptance of an individual's emotional status, recognition of the need for personal attention, and leveling the playing field to accommodate academic needs is some of the responsibilities that teachers have for establishing emotional security. The environment must hinge on spontaneity and structure. Schools are small communities where teachers preserve the dignity of learners by providing activities that give students a sense of belonging and connection in an environment that allows for the free exchange of ideas and, thus, learning. According to Ali \& Farah (2008), it is preceded with avoidance of a few gatherings that conflicts with the accomplishment of EFA objectives and the MDGs. Whereas, in the opinion of Avissar (2015), quality projects are worked via prepared teachers, use child's focused methodologies, draw in families and groups in kids' learning, backing kids' native language dialect, utilize socially significant materials and offer chances to play and investigate. These concepts are supported by Wechsler, Melnick, Maier,\& Bishop(2016) and Weikart(1999).

More and more pre-school programs continued to pop-up, mostly in rich, urban neighborhoods, especially after World War 2, as more mothers continued to join the work force. It is interesting to note that ECCE programs were driven by different agendas in developing countries than in developed ones. Jordan, Wolf \& Douglass (2012) support this notion followed by Juma (2004) who emphasized that improving the activities in ECE programmes is essential for productivity and sustainability. This was also endorsed by another study which assesses that emotional support from parents and other stakholdes is s essential in ECC curricula as other objectives for a balanced and effective ECE prgramme. Berube, Gaston, \& Stepans (2004) say that the policy for ECE and ECD is a "living record" that will stay for an uncertain period and be subjected to changes at whatever point any such prerequisite is felt.

Boyd (2001) is of the opinion that a way of critically thinking in terms of sending a small child of two and a half to three further highlights the negative impact of a baby being pulled from its mother's lap to be trained by individuals which the child is forced to become familiar with. In this context, it is worth noting the experiences of Hohmann (2002) whose guide to educating the young learners is an asset to the research on ECE programmes and teachers' professional development. Woodhead (2006), Wright (2018), Wylie, Mitchell \& Carr (2008) analyzed the functions of early childhood curricula and proposed experiences to be developed. Such notion is present in the most recent times too across the institutions 
that offer ECE an ECD programmes across Pakistan.ECE arguments are supported by Ismail (1999) who is an advocate of ECE development in Pakistan through federal and provincial support. Syed, Asif, \& Yousaf (2011) debated theECE contents prposed by the provincial authorities in Pakistan.

Anderson $(2011,2012)$ stress that mindset of the public how they think about children who are preschoolers and the importance that early childhood education has to be changed using many different ways and resources. This view is supported by Andrews (2012 and Andrews (1987) that through different mediums should be provided to the public about the importance of education for both male and female ECE children. Villegas-Reimers (2003) believes that the training for teachers and staff for the early learning centers should be given special attention to and the salaries should be provided to ensure a decent lifestyle for the teachers to make them meet their everyday needs with respectability in the society. Experts agree that this tight procedure of getting admission in quality early learning centers creates a tug of war between the public and creates disparity and hopelessness whose children do not get admission in early learning centers of quality. In th recent times, the work of SirajBlatchford (2009) has earned considerable attention of researchers and curriculum developers of ECE. Their work is a significant example of professional development and training. The policies required for ECE programmes. This was earlier advocated by Suverkrop (2002). The studies talk about the assessment of professional development, intervention and administrative excellence to augment the basic needs of young learners. Bueno, Darling-Hammond, \& Gonzales (2010) analyze that the training of the teachers of early education is not seen as a must and necessity to be continuous and, on a regular and proper checkup basis for teachers of early childhood education regarding latest methods and strategies as well as the latest updated knowledge about the progress in early learning education. Experts debated that ECE education in eastern culture is considered to be the only essentiality for becoming an early childhood education teacher, but that is not enough as early childhood education for early childhood teachers should be integrated into the bachelor of teacher education progressing towards the master of teacher education for becoming an expert and continuous professional development should be ensured even then.

Manning, Garvis, Fleming, \& Wong (2017) and Maurer (2012) have shown a positive attitude towards teachers making small children do their home chore as well as extra burdensome chores in the early learning centers such as sweeping the classes and school compounds, arranging furniture or carrying items. Bredeson (2002) affirms that there is no necessity seen, nor the following of any law for all kids of the schools of early learning years to be attending these early learning centers as a compulsion. Toru \& Manzoor (2015) argue that it is essential for ECE teachers to decid what the curriculum for small children will do to them once in force. 
Mbiti (1994) also emphsised the professional development programme for teachers with various needs and requirement. They assert that development of teachers is most integral aspect of professional teachers.

Byington \& Tannock (2011) are of the view that the questionable and somewhat shocking mindset regarding early child hood education for children, that is discovered in parents, through interactions, through television plays and actions is that the early learning education serves just useful to have the child out of the house, as the younger the kids the more patience, attention and understanding they require from parents.

\section{The Debate of ECCE Curriculum}

There are many aspects to consider when it comes to the actual implementation of ECCE initiatives, but perhaps none more so important than the curriculum utilized in the classrooms. The type of curriculum will influence the style of teaching that will be utilized, the goals that educators will strive for, and the general effectiveness of the ECCE program (Morrison, Woika, \& Breffni, Fundamentals of Early Childhood Education, 2019).Finally, the Project Approach, as defined by Drs. Chard and Katz, involves teaching students by getting them involved in projects, which are defined as a thorough examination of real-world topics that are relevant to, and capture the interest of, students. These projects are not the sole means of instruction though; rather, they serve as an addendum to a regular education system (Katz, Chard, \& Kogan, 2014).

\section{Material and Methods}

The strategy of the study comprised actions to reasons to improve the quality of teaching and professional development of ECD teachers in Pakistan. Since the population was large, the sample design for the study was stratified and random. A mixed method approach was adapted to complete the study. The questionnaire for the survey was prepared from the relevant literature, consultation with experts and personal experiences to conduct a survey whose main purpose was to gather detailed information to investigate the reasons of professional development of early childhood education teachers in Pakistan.

\section{Research Design}

Exploration has own particular nature and purposes. There are distinctive sorts of studies and each of these varies from other in its nature, complexity, sampling procedures population parameters and data collection procedures. The current study employed survey and descriptive analysis along with test of hypothesis. The research design also constituted the basic components of the study comprising sampling, population parameters and processes. Since the study was focused more on the testing of ten hypotheses, the study considered the descriptive study bass on the survey analysis out of the four types of quantitative approach. 
Descriptive design is used to report the basic parameters of the population characteristics. Correlation design is used to seek relationship between the independent and dependent variables on scaled data. Karl Pearson Co-efficient of correlation also known as Perason product moment formula is used in this design.

Causal comparative research is used when we are probing to determine the cause, or reason, for pre-existing differences in groups of individuals. This research design is also called "Ex Post Facto" design because both the assumed or hypothesized cause and the subsequent effect have already happened and is to be studies retrospectively. The selected samples were contacted using the APA manual and other guidelines for such processes. The selection and invitation to the samples were also done according to the approved format by the institutional authority and the consent of the research supervisor. The psychodynamic characteristics of the ECE teachers were selected as the main variable of the study samples who participated in the study. The components of the research study comprised all necessary measures including the selected samples, population characteristics, the discussion on the research instrument and the mechanism to analyze the instrument in the light of collected data. This study was also guided by the approved protocol as in the specialized area of educational research for ECE. Expected variables in the literature and the sampling procedures were of specific interest to the investigator. The approach of this study was a mixed methodology employing qualitative and quantitative techniques. Different parts of qualitative techniques were in the study. The rationale behind taking this method was to use the best opportunity to achieve the purpose of the study and address the planned research questions

\section{Population of the Study}

The population of the study consists on the teachers of ECE institutions across the Sindh province and specifically in the two districts of Karachi and Hyderabad where these institutions were abundant and easy to access. Some of the early childhood Practitioners in Pakistan were also contacted from other cities of the country. All ECD and ECE teachers in Pakistan are the target population of the study.

\section{Sampling Procedure}

Since the population is large, the specific sample design for the study was stratified and random sampling. A stratified research sampling procedure comprises the parts of the population into a small section with similar characteristics called strata. Each stratum represents the sub group characteristic in the same proportion as it exists in the real population. Shared attributes and characteristics are the major signs of this stratification. On the other hand, a random sampling procedure comprises the samples to be selected with equal probability. This is known as the best sampling methods as no known researcher's bias is present in the procedure. A fixed number is set to be selected in the sampling frame to represent the study with 
normal and natural characteristics. The study also employed the representative samples through the methods discussed above.

\section{Sampling Characteristics}

The following sampling characteristics were observed in the study for ensuring the homogeneity and avoiding outliers and heterogeneity. A homogenous sample is professionally more adequate to address the issues of random bias in a random variable. It also helps in controlling the fixed and random effect depending on the research needs.

- Each teacher of ECE was trained with a certificate of a diploma from a recognized institution in the country.

- All teachers of observed institutions were between the ages of 24 to 32 years of age.

- No teachers in the ECE programmes in both the cities were working as ful time anywhere else except their mother institutions.

- All ECE teachers were able to communicate with the students in both Urdu and English language.

- All teachers of ECE had received professional training through workshops and seminars within and outside the city as requirement of continuous professional growth.

- All teachers of the ECE programme observed in the study knew Islamic procedures to raise and develop a child. It was obvious in their curricula too.

- The salary paid to the ECE teachers ranged between Rs 26,000 to Rs. 47,000 per month.

- All ECE teachers had served in their capacity of ECE teachers for a minimum period of six years.

\section{Research Instruments}

After specifying the population and drawing the sample, the next step was to collect data for solving the problem under study. Questionnaire, interview protocol and record analysis were main research instruments. Questionnaire was used for collection of data. It is found useful in many ways as it is economical, suitable for group administration. It can reach the respondents scattered over a wide spread area and it ensures uniformity of procedure. Two self-reporting procedures, questionnaire and interviews were specially designed and used. The questionnaire 
consisted of 30 items prepared from the relevant literature, consultation with the expert, research supervisor and personal experiences.

\section{Results and Discussion}

The hypotheses in the analysis were drawn from the review of related literature. The survey findings were analyzed linearly, and cross sectionally in order to have a better understanding between the relationship of dependent and independent variables, moderating, and intervening variables. The empirical results or the survey findings and interpretations of the study are discussed below. A sample of $n=396$ participants responded to various items in the questionnaire.

\section{Hypothesis 1}

There will be no significant difference among ECE teachers having inventive personality trait and ECE teachers having cautious personality trait in their professional development.

Table 1. Inferential Statistics of ECE Teachers

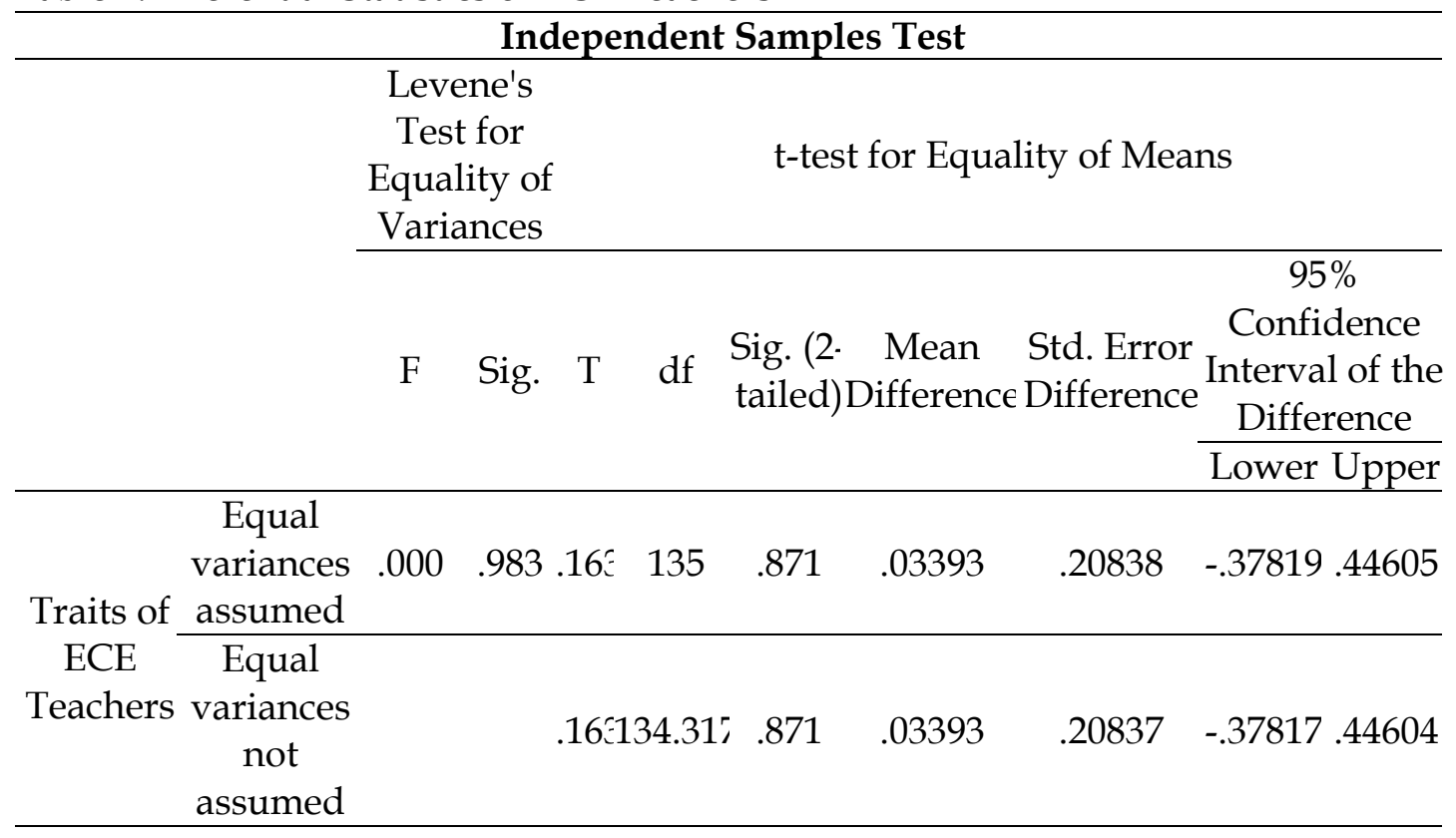

Table 1 illustrates that the significance of the test is not proven as the F-value significance is 0.98 which is $>0.05$, type I error. The $t$-value is 0.163 resulting from independent sample t-test against $0.871>0.05$ as the level of significance. The upper and lower confidence intervals have a zero lying between them confirming that there is no significant difference between the inventive and cautious teachers of ECE who were sampled in the study.

\section{Hypothesis 2}


There will be no significant difference among ECE teachers having curious personality trait and ECE teachers having consistent personality trait in their professional development.

Table 2

Inferential Statistics of ECE Teachers

Levene's Independent Samples Test

Test for

Equality of

t-test for Equality of Means

Variances

$95 \%$

F Sig. $\quad t \quad$ Df $\begin{aligned} & \text { Sig. (2. Mean Std. Error } \begin{array}{c}\text { Confidence } \\ \text { tailed)Difference Difference }\end{array} \\ & \text { Interval of the }\end{aligned}$

Difference

\begin{tabular}{ccccccccc}
\hline \multicolumn{2}{c}{$\begin{array}{c}\text { Equal } \\
\text { Traits of } \\
\text { ECE } \\
\text { variances } \\
\text { assumed }\end{array}$} & .041 & $.841 .15 \longleftarrow$ & 135 & .878 & .03286 & .21282 & -.38803 .45376 \\
$\begin{array}{c}\text { Teachers } \\
2\end{array}$ & $\begin{array}{c}\text { Equal } \\
\text { variances } \\
\text { not } \\
\text { assumed }\end{array}$ & & & $.15 £ 134.606$ & .877 & .03286 & .21267 & -.38774 .45347 \\
\hline
\end{tabular}

Table 2 illustrates that the significance of the test is not proven as the F-value significance is 0.841 which is $>0.05$, type I error. The $t$-value is 0.154 resulting from independent sample t-test against $0.878>0.05$ as the level of significance. The upper and lower confidence intervals have a zero lying between them confirming that there is no significant difference between the curious and consistent teachers of ECE who were sampled in the study.

\section{Key Findings}

The ECE system of Pakistan is very demanding for the child in which the child is expected to know a lot without understanding the content at times and this leads to the pressure and competition to connect the child to the demanding school world. This is also one of the factors for the development of ECD and ECD. The ECE and ECD present a more civilized and modernized system as compared to the katchi classes which seem quite unfashionable even in name as compared to the new program of ECD and ECE so the eyes of the world are on developing countries such as Pakistan to eradicate its tensions of the past which the country had been facing by the introduction of ECE and ECE as a solution for the past problems and for developing peace in the minds of the citizens in their youngest forms. 
In some private ECE institutes, there is a lot of competition for admission. It is not only on first-come-first-served basis, but admission forms have to be bought and there are tests and interviews the child has to successfully pass in, in order to get admission in the ECD and ECE program. The child's parents have to pay admission fees as well as school fees when the child is enrolled in the early childhood education institute. The public institutes for ECE and ECD mostly present quite a bleak picture as provision of learning equipment as well as the infrastructure is not so good as compared to the private ECE and ECD programs. The teachers of the public institutes, though they have teacher training of ECE and ECD, are not so interested in doing their best and are not so conscientious due to the poor check and balance system in the public ECE and ECD institutes.

The use of technology for the children born into the world of technology will obviously prove fruitful in the ECE and ECD classrooms. The children feel more at ease to express their wanting to see or hear particular things by tapping on letters which they cannot identify, but know that when they press these symbols, they get a certain result. Children, mysteriously know the message a symbol carries even before knowing what the symbol sounds like or the meaning of the symbol. Giving preschoolers the use of tablets and devices, which represent what the children want to say even before they can verbally express themselves, gives all kinds of ECE and ECD learners an ease and confidence that barrier of verbal communication cannot act as an obstacle for their expression.

ECD and ECE classes in Pakistan suffer because of the lack of integration of technology in the classes due to various issues such as expenses, insufficient training of teachers, non-availability of sufficient technology equipment, uneasiness while handling technological equipment and last, but not least and something that can be said to be a major issue, is the power breakdowns which cover with darkness all possibilities of shedding the light of hope for using technology in the classroom. The mindset of the teachers has to be changed, the availability of sufficient equipment has to be catered to, and the issue of power breakdowns has to be solved with easily available and operational generators with sufficient fuel for long usage and usage whenever needed.

The use of technology in the ECE classrooms has to be an important part of the curriculum for ECE and ECD as proper funding and attention has to be given to this issue. Technological equipment instead of being imported from other countries should be developed in our own country and import from other countries for technological equipment should be stopped so that the citizens can have the equipment made in Pakistan at affordable prices. This will enable and ensure that the ECE and ECD classes will never have shortage or unavailability of technological equipment. 


\section{Conclusion}

A suitable curriculum for the ECD and ECE program is determined by the various psychological theories, concepts of philosophers and inspiration of scientific minded experts, pressure agencies and various issues pertaining to funding and permission of what can be implemented into the Islamic ideological country of Pakistan. Mamede-Neves (2015) describes the same conclusion in the study for an effective and robust ECD programme considering the professional development of teachers and children. There are additional reasons for the development of the curriculum for ECE and ECD and from among those a crucial reason can be to provide a sort of atmosphere and suitable conditions for learning for the essential development of a child and consideration of what curricula the child should be exposed to make him/her into a conscientious, responsible and civilized citizen of Pakistan. The curriculum development of ECE and ECD in Pakistan is done, keeping in mind the ideology and values of the way the Pakistani society wants to bring up the toddler for wearing and walking in the shoes of an adult Pakistani. The curriculum development for the ECE and ECD program in Pakistan is done for the development of the child as the vision we all have of what a patriotic and countryloving Pakistani should be like. The curriculum also explores the desire to see future scientists, inventors, economists, doctors and a future for Pakistan in politics to see Pakistan reflected in the young learners. It is also the future vision to shine out in the future to see the ECE children develop into professionally competent individuals. .

The curriculum is developed keeping in mind the psychological, emotional, cultural, social and various other determinants of the Pakistani future generation. This debate is upheld by Kucukturan (2011), Larson, Larson \& Wiatros (2018) who also believe that professional development of ealy childhood education teachers is necessary. The curriculum of ECE faces the challenges of harnessing the young developing minds and the expectations of the miraculous brain of the three-year old to soak in as much as possible and to develop the elements for a prosperous development of the learning, knowing and performing potential in the child. The ECE curriculum developed, has to consider the different kinds of learners who enter the ECE and ECD classroom and are from different backgrounds, culture, home environments, face issues of different languages and mannerisms so a curriculum of ECE and ECD has to be developed to be tailored to and to suit all the different learners.

Pakistan has added the ECE and ECD program in its curriculum as Pakistan also needs to come up to the Sustainable Development Goals to be attained by 2030 that it signed up for and Educational for All. This means also covering the education of the ECE child from the very early years for the holistic development of the child from a very early age. Through this measure, not only the Pakistani society will benefit from such an individual, but the individual himself will grow up to become an efficient and responsible citizen to have a hand in the future progress and success of the country. The ECE curriculum development in Pakistan is a need, necessity, a 
future and a struggle to prove that Pakistan can come up to the developed countries and also become an instigator of peace.

\section{Recommendations}

The research and its findings have important implications for ECE teachers, educators, and for the researchers. Some of strongly expressed needs for teachers in the study were in fact the dire need for understanding the significance of personality traits for the self-development of ECE teachers. The implication is clear. The EC teacher must create a self-motivational environment where their self- development is nurtured and sustained so that teachers can emphasis on self- development with reference to their professional development and growth.

The imperative issue for the ECE and ECD program to develop and take root and develop into a fruitful tree is a need for the future generations to have embedded and flourishing in them the early years of education to develop the young ones to their full potential. Steps have been taken to develop the ECE and ECD programme since the mention of ECE in the National education policy of 2017, but work is still in progress as the concept of katchi classes posed a picture of things and learning happening monotonously. The proper idea of what is good for a child and how and what a child should learn and in what way is still not very clear to the Pakistani public. 


\section{References}

Ackerman, C. (2019). Big Five Personality Traits: The OCEAN Model Explained [2019 Upd.].

Ackerman, R., \& Maslin-Ostrowski, P. (2002). The Wounded Leader: How Real Leadership Emerges in Times of Crisis. The Jossey-Bass Education Series. Jossey-Bass.

Ali, S., \& Farah, I. (2008). Schooling in Pakistan. In A. Gupta (Ed.), Going to school in South Asia (pp. 143-166). Greenwood Press.

Anderson, D. W. (2011). Hospitable Classrooms: Biblical Hospitality and Inclusive Education. Journal of Education and Christian Belief, 15(1), 13-27.

Anderson, D. W. (2012). Toward a Theology of Special Education: Integrating Faith and Practice. WestBowPress.

Andrews, H. A. (2012). Supporting Quality Teaching with Recognition. Australian Journal of Teacher Education, 36(12), 59-70.

Andrews, R. N. L., \& Soder, R. (1987). Principal Leadership and Student Achievement. Educational Leadership, 44(6), 9-11.

Armstrong, D. M. (2007, November 1). A Case Study of the Effectiveness of an ECE Teacher Education Program. SoTL Commons Conference.

Ashraf, D (2013). Youth development and education in Pakistan: Exploring the relationship. Sisyphus - Journal of Education, 1(2), 162-192.

Aubrey, R. H. (1998). Moral Purposes of Successful Teachers [East Tennessee State University]. In Electronic Theses and Dissertations.

Avissar, G. (2015). Professional Development of Teacher Educators: Bringing Together Policy, Practice and Research (pp. 93-102). Association for Teacher Education in Europe.

Bereiter, C., \& Engelmann, S. (1998). Teaching Disadvantaged Children in the Preschool. Prentice-Hall.

Bertsch, K. M., Houlihan, D., Lenz, M. A., \& Patte, C. A. (2017). Teachers' Commands and their Role in Preschool Classrooms. Electronic Journal of Research in Education Psychology, 7(17), 133-162.

Berube, W., Gaston, J., \& Stepans, J. (2004). The role of ECE principal in teacher professional development. NOVAtions Journal, 1. 
Boyd, G. (2001). Early childhood teachers' perceptions of their leadership roles [Edith Cowan University]. In Theses: Doctorates and Masters.

Bredeson, P. V. (2002). Designs for Learning: A New Architecture for Professional Development in ECE Schools. Corwin Press, Inc.

Bueno, M., Darling-Hammond, L., \& Gonzales, D. (2010). A Matter of Degrees: Preparing Teachers for the Pre-K Classroom Education Reform Series.

Byington, T. A., \& Tannock, M. T. (2011). Professional development needs and interests of early childhood education trainers. Early Childhood Research and Practice, 13(2).

Daries, J., Engdahl, I., Otieno, L., Pramling-Samuelson, I., Siraj-Blatchford, J., \& Vallabh, P. (2009). Early Childhood Education for sustainability: Recommendations for development. International Journal of Early Childhood, 41(2), 113-117.

Hohmann, M. (2002). A Study Guide to Educating Young Children: Exercises for Adult Learners (2nd ed.). High/Scope Press.

Hohmann, M., \& Weikart, D. P. (2002). Educating Young Children: Active Learning Practices for Preschool and Child Care Programs (2nd ed.). Scope Press.

Ismail, S. (1999). An Evaluation Study of Early Childhood Education in Pakistan [Hamdard University]. http:// prr.hec.gov.pk/jspui/handle/123456789//4128

Jordan, J. R., Wolf, K. G., \& Douglass, A. (2012). Increasing Family Engagement in Early Childhood Programs. Young Children, 1(7), 18-23.

Juma, A. (2004). Improving Practices in Early Childhood Classrooms in Pakistan: Issues and Challenges from the Field. Contemporary Issues in Early Childhood, 5(3), 402-407.

Katz, L., Chard, S. C., \& Kogan, Y. (2014). Engaging Children's Minds: The Project Approach (3rd ed.). Praeger.

Katz, R. L. (1955). Skills of an Effective Administrator. Harvard Business Review, 33, 33-42.

Maurer, A. B. (2012). The Impact of Positive Traits on Teacher Performance WithinA Systems-Driven Charter School Management Organization. In Master of Applied Positive Psychology (MAPP) Capstone Projects (No. 34).

Mbiti, D. M. (1994). Foundations of pre-school administration. Oxford UniversityPress.

Goldberg, L. R. (2007). An Analysis of a Cross-Cultural Personality Inventory: The 
IPIP Big-Five Factor Markers in Croatia. Journal of Personality Assessment, 88(2), 168177.

Morrison, G. S. (2018). Early Childhood Education Today (14th ed.). Pearson.

Morrison, G. S., Woika, M. J., \& Breffni, L. (2019). Fundamentals of Early Childhood Education (9th ed.). Pearson.

Newcomb, M., \& Ritter, G. (2011). Raising the ECE and Kindergarten Entry Age. Policy Briefs, 8(8).

Pakistan Ministry of Education. (2009). National Education Policy 2009. Ministry of Education Islamabad

Suverkrop, C. (2002). Teacher evaluation as professional development [California State University, Monterey Bay]. In Capstone Projects and Master's Theses.

Syed, S., Asif, M., \& Yousaf, A. (2011). Rethinking ECE in Pakistan. Journal of Elementary Education, 21(2), 65-76.

Toru, S. K., \& Manzoor, R. (2015). Magnifying the Gaps: Situation Analysis of Early Childhood Education Development in KPK, Sindh. Parwaan.

Villegas-Reimers, E. (2003). Teacher professional development: an international review of the literature. International Institute for Educational Planning.

Wechsler, M., Melnick, H., Maier, A., \& Bishop, J. (2016). The Building Blocks of HighQuality Early Childhood Education Programs. Cambridge University Press.

Weikart, D. P. (1999). The Cognitively Oriented Curriculum: A Framework for Preschool Teachers. National Association for the Education of Young Children.

Woodhead, M. (2006). Changing Perspectives on Early Childhood: Theory, Research and Policy. International Journal of Equity and Innovation in Early Childhood, 4(2), 143.

Wright, S. (2018). Teachers Have Emotions Too: An Intra | Interpersonal Approach to Exploring Emotions in Teacher Preparation Courses [City University of New York]. In CUNY Academic Works. 